\title{
Diazepam influences urinary bioindicator of occupational toluene exposure
}

\author{
Alberto Thalison Silveira ${ }^{a}$, Ana Carolina Campos Albuquerque ${ }^{a}$, José Salvador Lepera ${ }^{b}$, \\ Isarita Martins ${ }^{\mathrm{a}, *}$ \\ a Laboratory of Toxicant and Drug Analyses, Federal University of Alfenas, Unifal-MG, Alfenas, MG, Brazil \\ ${ }^{\mathrm{b}}$ Laboratory of Occupational Toxicology, Faculty of Pharmaceutical Sciences of Araraquara - FCFAr, UNESP, Araraquara, SP, Brazil
}

\section{A R T I C L E I N F O}

\section{Article history:}

Received 15 July 2016

Received in revised form 14 October 2016

Accepted 15 October 2016

Available online 18 October 2016

\section{Keywords:}

Toluene

Diazepam

Occupational exposure

o-Cresol

Hippuric acid

\begin{abstract}
A B S T R A C T
In the present study, we investigated the influence of diazepam (DZP) on the excretion of TOL by examining their urinary metabolites, hippuric acid (HA) and ortho-cresol $(o-C)$. Male Wistar rats were exposed to TOL $(20 \mathrm{ppm})$ in a nose-only exposure chamber ( $6 \mathrm{~h} /$ day, 5 days/week for 6 weeks) with simultaneous administration of DZP $(10 \mathrm{mg} / \mathrm{kg} /$ day $)$. Urinary $o-C$ levels were determined by GC-MS, while HA, creatinine (CR), DZP and its metabolite, nordiazepam, were analysed by HPLC-DAD. The results of a Mann-Whitney $U$ test showed that DZP influenced the urinary excretion of $o-C(p<0.05)$. This pioneering study revealed that there was an interaction between DZP and TOL, probably by the inhibition of the CYP isoforms (CYP2B6, CYP2C8, CYP2E1, and CYP1A2) involved in the oxidative metabolism of the solvent. This is relevant information to be considered in the biomonitoring of occupational toluene exposure.
\end{abstract}

(c) 2016 Elsevier B.V. All rights reserved.

\section{Introduction}

Toluene (TOL) is a volatile organic solvent that is largely used in industry and in a number of commercial products such as detergents, dyes, paints, adhesives, glues, and pharmaceuticals. Inhalation is the main route of human exposure to TOL, although it can be absorbed through the skin and the gastrointestinal tract (EPA, 2005). The occupational exposure limit for TOL is $78 \mathrm{ppm}\left(294.1 \mathrm{mg} / \mathrm{m}^{3}\right.$ ) in Brazil (MTE, 2014), while the updated threshold limit value-time weighted average (TLV-TWA) is $20 \mathrm{ppm}$ $\left(75.4 \mathrm{mg} / \mathrm{m}^{3}\right)$, as recommended by the American Conference of Governmental Industrial Hygienists in the United States (ACGIH, 2015). After inhalation, TOL readily crosses the blood-brain barrier and produces neurological effects comparable to those of sedativehypnotics such as alcohol and benzodiazepines (Win-Shwe and Fujimaki, 2010). Previous studies have suggested that TOL has anxiolytic and anticonvulsant effects by modulating $\gamma$-aminobutyric acid (GABA) release and $\mathrm{GABA}_{A}$ receptor function. It is important to mention that GABA is the main inhibitory neurotransmitter in

\footnotetext{
* Corresponding author at: Isarita Martins, Laboratory of Toxicant and Drug Analyses, Federal University of Alfenas-MG, Gabriel Monteiro da Silva St. 700, 37130-000, Alfenas, MG, Brazil.

E-mail address: isarita.sakakibara@unifal-mg.edu.br (I. Martins).
}

the central nervous system (Beckley and Woodward, 2011; PaezMartinez et al., 2013).

In the human liver, TOL is metabolized by cytochrome P450 (CYP), predominantly by CYP2E1 (followed by CYP2B6, CYP2C8, CYP1A2, and CYP1A1) to benzyl alcohol, which is easily converted to benzoic acid via aldehyde dehydrogenase and is excreted into urine as hippuric acid (HA). Ortho-cresol $(o-C)$ and para-cresol $(p-C)$ are formed by the catalytic action of CYP2E1, CYP1A2, and CYP2B6 as minor metabolites from TOL (EPA, 2005; Lee and Yang, 2008; Nakajima and Wang, 1994; Nakajima et al., 1997). Biological monitoring of occupational exposure to this solvent is based on unaltered urinary and blood TOL and their metabolites, HA and $o-C$. This approach has been adopted in most countries. For many years, HA has been the marker of choice. However, this metabolite is nonspecific and may arise from other sources, such as certain fruits and foods, which contain benzoic acid. The HA excreted in urine cannot be solely attributed to TOL exposure in concentrations below 50 ppm (Cosnier et al., 2013; Fustinoni et al., 2000).

As an alternative, urinary $0-C$ has been adopted as a determinant both in the biological exposure indices (BEI) and in the biological tolerance values for occupational exposures (BAT). A value of $0.3 \mathrm{mg} / \mathrm{g}$ of creatinine (CR) for samples collected at the end of the shift is suggested as a BEI, and a BAT of $1.5 \mathrm{mg} / \mathrm{L}$ for samples collected at the end of the shift after long-term exposure are listed (ACGIH, 2015; DFG, 2015). The "B" notation reported by ACGIH indicates that $\mathrm{o}-\mathrm{C}$ is usually present in a significant amount in 
biological specimens collected from non-occupationally exposed subjects (ACGIH, 2015).

According to Truchon et al. (1999), o-C performs similarly to HA as a marker at high exposure levels. In contrast, $o$-C appears to outperform HA at lower TOL concentrations (below $50 \mathrm{ppm}$ ). Urinary and blood TOL themselves are more specific to access the exposures; hence, the analysis of TOL in urine is most convenient due to its non-invasive sampling and higher volume available (Fustinoni et al., 2000; Netto et al., 2008). A BEI of $0.02 \mathrm{mg} / \mathrm{L}$ in blood and $0.03 \mathrm{mg} / \mathrm{L}$ in urine has been adopted to monitor TOL exposure (ACGIH, 2015).

Most contemporary regulations and risk assessments regarding toxic chemicals are still single-compound-oriented, even though in the general environment most workers are exposed to complex mixtures (Chang et al., 2005). Interactions between ethanol and solvents are well-known, but there have been few reports on the interactions between solvents and drugs (Døssing et al., 1984; Ernstgård et al., 1999; Wang and Nakajima, 1991, 1992). With the increasing consumption of therapeutic drugs in many countries, workers are often exposed to occupational chemicals and drugs. Adequate knowledge and/or sufficient assessment of situations affecting the levels of bioindicators may be necessary to avoid incorrect interpretations of the results of biological monitoring (Campbell et al., 1988; Døssing et al., 1984).

Diazepam (DZP) has been used in a wide spectrum of disorders due to its anticonvulsant, anxiolytic, sedative, muscle relaxant, and amnestic properties. It is also routinely prescribed as the standard first-line treatment for acute convulsions and prolonged status epilepticus (Alldredge et al., 2001; Sweetman, 2009). The metabolic pathway of DZP involves a variety of CYPs, which are responsible for their three major active metabolites: $N$-desmethyldiazepam or nordiazepam (NOR), oxazepam (OX), and temazepam (TZ). DZP C3hydroxylation is mediated by CYP2C19, 3A4, and 3A5 and leads to TZ, whereas $N$-demethylation leading to NOR is mediated by CYP2B6, 2C8, 2C9, 2C18, 2C19, 3A4, and 3A5. NOR and TZ, the primary metabolites of DZP, are oxidized further to OX, which is excreted mainly in the urine, predominantly as glucuronide conjugates. In time, the metabolite NOR is metabolized by CYP3A4, 3A5, and 2C19 via C3-hydroxylation to form OX. In contrast, TZ is demethylated by CYP3A4, 2C19, 3A5, 2C8, 2C9, and 2B6 to create OX (Acikgöz et al., 2009; Yang et al., 1998).

Metabolic interactions may have implications for biological monitoring when $o-\mathrm{C}$ and $\mathrm{HA}$ are used to assess TOL uptake in exposed workers. Thus, taking into account the high frequency of BZP utilization in clinical practice and the large number of workers who are exposed to solvents, the present study was conducted with rats to investigate the effects of DZP on TOL metabolism by examining their metabolites.

\section{Materials and methods}

\subsection{Chemicals}

The study was performed with the following commercially available standards: toluene - 99.\% Sigma-Aldrich ${ }^{\circledR}$, Steinheim, Germany; isopropylbenzene - 98\% Sigma-Aldrich ${ }^{\circledR}$, Steinheim, Germany; hippuric acid - 99\% Sigma-Aldrich ${ }^{\circledR}$, Saint Louis, USA; creatinine - >98\% Sigma-Aldrich ${ }^{\circledR}$, Saint Louis, USA; ortho-cresol-d - >98\% Sigma-Aldrich ${ }^{\circledR}$, Steinheim, Germany; ortho-cresol - 99.9\% Sigma-Aldrich ${ }^{\circledR}$, Steinheim, Germany; nitrazepam $100 \mu \mathrm{g} / \mathrm{mL}$ 99.97\% Sigma-Aldrich ${ }^{\circledR}$, Saint Louis, USA; diazepam - 100\% União Química Farmacêutica Nacional $S / A^{\odot}$, Pouso Alegre, Brazil; and nordiazepam - 100\% União Química Farmacêutica Nacional $S / A^{\circledR}$, Pouso Alegre, Brazil. The following analytical-grade reagents were used: PEG 400 (polyethylene glycol) - Sigma-Aldrich ${ }^{\circledR}$, Saint Louis, USA; carbon disulfide - Sigma-Aldrich ${ }^{\circledR}$, Saint Louis, USA; potassium dihydrogen phosphate - Proquímica ${ }^{\circledR}$, Rio de Janeiro, Brazil; acetonitrile - Lichrosolv ${ }^{\circledR}$, Darmstadt, Germany; sulfuric acid - Vetec ${ }^{\circledR}$, Rio de Janeiro, Brazil; $\mathrm{Na}_{2} \mathrm{CO}_{3}$ (sodium carbonate) - $\mathrm{CAAL}{ }^{\circledR}$, São Paulo, Brazil; diisopropyl ether - Honeywell ${ }^{\circledR}$, Seelze, Germany; sodium hydrogen phosphate - Caal ${ }^{\circledR}$, São Paulo, Brazil; $n$-hexane - Honeywell ${ }^{\circledR}$, Morristown, USA; ethanol - Química Moderna ${ }^{\circledR}$, Barueri, Brazil; potassium dihydrogen phosphate - Proquímica ${ }^{\circledR}$, Rio de Janeiro, Brazil.Ultra-pure water $(18.2 \mathrm{M} \Omega / \mathrm{cm})$ was obtained from a Millipore ${ }^{\circledR}$ system.

\subsection{Animals}

Male Wistar rats weighing approximately $250 \mathrm{~g}$ were used for the study. The animals' room was maintained at a temperature of $20 \pm 1{ }^{\circ} \mathrm{C}$ and $60 \pm 20 \%$ relative humidity, with a 12-h light-dark cycle. Rat chow (Presence ${ }^{\circledR}$, Paulínia, Brazil) and tap water were available ad libitum, except during exposure procedures. The rats were divided into 4 groups ( 5 rats per group): control, GDZP, GTOL, and GTOL/DZP groups.

\subsection{Experimental design}

The animals used in this study were handled in accordance with the Guide for the Care and Use of Laboratory Animals adopted by the Brazilian Association for Laboratory Animal Science (COBEA). The protocol that was followed was approved by the Ethics Committee for Use of Animals (27/2015) of the Faculty of Pharmaceutical Sciences, São Paulo State University, Araraquara.

In the first group (GTOL), rats $(n=5)$ treated with diluent (PEG 400:saline solution - 70:30, vol/vol) were exposed to TOL $(99.9 \%$ pure) at $20 \mathrm{ppm}$ (TLV-TWA) in a nose-only inhalation chamber for $6 \mathrm{~h} /$ day, 5 days/week for 6 weeks (Cardoso et al., 2015). For the 6-h exposure period, the rats did not have access to food or water. In the second group of animals (GTOL/DZP), 20 min prior to TOL exposure (as previously mentioned), $10 \mathrm{mg} / \mathrm{kg}$ DZP dissolved in diluent was administered by gavage to rats $(n=5)$.

In the third group (GDZP), rats $(n=5)$ were exposed to filtered air in a nose-only inhalation chamber ( $6 \mathrm{~h} /$ day, 5 days/week for 6 weeks). Additionally, $20 \mathrm{~min}$ before TOL exposure, $10 \mathrm{mg} / \mathrm{kg}$ DZP dissolved in diluent was administered by gavage. A control group with unexposed rats $(n=5)$ was treated with diluent and exposed to filtered air.

\subsection{Nose-only inhalation exposure}

The nose-only inhalation chamber consisted of two planes (top and bottom) with 24 ports each, as previously described (Cardoso et al., 2015). Before the exposures, the generation of the controlled atmosphere of TOL was validated by examining fluctuations in TOL concentration between doors (homogeneity) and for the 6-h exposure period (stability). Air samples from the inhalation chamber were collected using glass tubes packed with activated charcoal Anasorb CSC 100/50 mg (SKC ${ }^{\circledR}$, Blandford Forum, UK). The TOL collected was desorbed from the activated charcoal with carbon disulfide. Isopropylbenzene was added as an internal standard (IS), and samples were analysed on a Perkin Elmer ${ }^{\circledR}$ Clarus 680 gas chromatograph (GC) (Massachusetts, USA) equipped with a flame ionization detector. The TOL samples were assayed on a $30 \mathrm{~m} \times 0.25 \mathrm{~mm} \times 1.4 \mu \mathrm{m}$ film thickness Elite-624 capillary column (Perkin Elmer ${ }^{\circledR}$ ). The column oven temperature was programmed at $60^{\circ} \mathrm{C}$ for $1 \mathrm{~min}$, then increased to $110^{\circ} \mathrm{C}$ at a rate of $20^{\circ} \mathrm{C} / \mathrm{min}$. Subsequently, the column temperature was raised to $180^{\circ} \mathrm{C}$ at a rate of $10^{\circ} \mathrm{C} / \mathrm{min}$, then maintained at $180^{\circ} \mathrm{C}$ for $1 \mathrm{~min}$. The injector 
temperature and detector temperature were maintained at $180^{\circ} \mathrm{C}$ and $200^{\circ} \mathrm{C}$, respectively.

\subsection{Sample collection}

Following the conclusion of the final inhalation exposure, the animals were placed in individual metabolic cages with free access to food and water from 4:00 pm to 8:00 am the following day. For this 16 -h period, urine samples were obtained in collection tubes. The samples were frozen immediately after collection and stored at $-70^{\circ} \mathrm{C}$. To account for variability in urine volume, metabolite concentrations were expressed relative to CR concentration.

Animals were sacrificed by decapitation $16 \mathrm{~h}$ after the last exposure (steady state), and the whole blood was collected in heparinized tubes. Blood samples were centrifuged, and the plasma was separated and immediately frozen at $-70^{\circ} \mathrm{C}$ until the analysis.

\subsection{HA and $C R$ analysis}

HA and CR concentrations were determined as previously described (Antunes et al., 2008). Briefly, the urine and standard samples were first diluted with ultrapure water $(1: 10$, $\mathrm{vol} / \mathrm{vol})$. Then, each sample was centrifuged $(715 \mathrm{~g}$ ) for $10 \mathrm{~min}$. An aliquot of $400 \mu \mathrm{L}$ from the supernatant was transferred to a high-performance liquid chromatography (HPLC) autosampler vial, and $20 \mu \mathrm{L}$ were injected into the chromatographic system. An HPLC Shimadzu ${ }^{\circledR}$ was coupled to the UV-vis detector set at $225 \mathrm{~nm}$. Chromatographic separations were performed at a flow rate of $1 \mathrm{~mL} / \mathrm{min}$ on a CLC-ODS (M) column $(150 \mathrm{~mm} \times 4.6 \mathrm{~mm}$, $5 \mu \mathrm{m})\left(\right.$ Shimadzu ${ }^{\circledR}, K$ Kyoto, Japan). The mobile phase was a mixture of potassium dihydrogen phosphate buffer ( $50 \mathrm{mmol} / \mathrm{L}, \mathrm{pH} 2.3$ ) and acetonitrile (85:15, vol/vol), which was filtered and sonicated before use. The column oven temperature was $30^{\circ} \mathrm{C}$. Total run time was $8 \mathrm{~min}$. Standard curves were constructed using rat urine spiked with $\mathrm{HA}$ and $\mathrm{CR}$ to provide a final concentration for each analyte of $250-5000 \mathrm{mg} / \mathrm{L}$ of urine. The recoveries of both metabolites were in the range of 101-106\%, regardless of HA and CR concentration. The relative standard deviation $(R S D \%)$ and relative error $(E \%)$ for intra- and inter-assay precision and accuracy, respectively, were less than $15 \%$.

\section{7. o-C analysis}

The concentration of $o$ - $\mathrm{C}$ in the rat urine were measured according to Cosnier et al. (2013), with slight modifications. Briefly, $50 \mu \mathrm{L}$ of sulfuric acid (95\%) were added to a $0.6 \mathrm{~mL}$ aliquot of urine to hydrolyse the cresol conjugates. After it was shaken, the mixture was heated at $95^{\circ} \mathrm{C}$ for $2 \mathrm{~h}$ and allowed to cool to room temperature. Excess acidity was neutralized with $1 \mathrm{~mL}$ of $\mathrm{Na}_{2} \mathrm{CO}_{3}(100 \mathrm{~g} / \mathrm{L})$, then $50 \mu \mathrm{L}$ of a $6-\mathrm{mg} / \mathrm{L}$ aqueous solution of ortho-cresol- $\mathrm{d}_{8}\left(0-\mathrm{Cd}_{8},>98 \%\right)$ were added as internal standard (IS). Additionally, the analytes were extracted with $500 \mu \mathrm{L}$ of diisopropyl ether. The mixture was shaken for $15 \mathrm{~s}$. After separation of the two layers by centrifugation at $715 \mathrm{~g}$ for $10 \mathrm{~min}$, approximately $300 \mu \mathrm{L}$ of the upper organic layer were collected and analysed. Gas chromatographic-mass spectrometric (GC-MS) analysis was performed using a GC-MS QP2010 from the Shimadzu Corporation ${ }^{\circledR}$ (Kyoto, Japan) equipped with a ZB-Wax $(30 \mathrm{~m} \times 0.25 \mathrm{~mm} \times 0.25 \mu \mathrm{m}$ film thickness $)$ capillary column (Phenomenex ${ }^{\circledR}$, Torrance, California, USA) in electronic impact mode ( $70 \mathrm{eV})$. Pure helium (99.999\%) with a column flow of $1.0 \mathrm{~mL} / \mathrm{min}$ was used as the carrier gas. An aliquot of $1 \mu \mathrm{L}$ from the standard sample was injected in the splitless mode and analysed under the following conditions. The oven temperature was programmed at $140^{\circ} \mathrm{C}(8 \mathrm{~min})$, then increased to $225^{\circ} \mathrm{C}$ at a rate of $25^{\circ} \mathrm{C} / \mathrm{min}$ (maintained for $2.5 \mathrm{~min}$ ) before finally being increased to $250^{\circ} \mathrm{C}$ at $25^{\circ} \mathrm{C} / \mathrm{min}$ (maintained for $1 \mathrm{~min}$ ). The total run time was $15.9 \mathrm{~min}$. The injector, interface, and ion source temperatures were $250^{\circ} \mathrm{C}, 250^{\circ} \mathrm{C}$, and $178^{\circ} \mathrm{C}$, respectively. The quantitative analyses were completed in selected ion monitoring mode (SIM) with an event time of $0.1 \mathrm{~s}$ for each analyte.

Ion mass-to-charge $(\mathrm{m} / \mathrm{z})$ ratios 108 and 115 were used to quantify $o-C$ and $o-\mathrm{Cd}_{8}$, respectively. Ions at $m / z 108,107$, and 77 were employed to confirm the identification of $o-C$. A standard curve was constructed using rat urine spiked with $o-C$ to yield a final concentration of $0.06-2.4 \mathrm{mg} / \mathrm{L}$ of urine. Quantification was based on the ratio of the chromatographic peak area of the analyte to the relative internal standard. Recovery was in the range of $70 \%-86 \%$, regardless of $o$-C concentration. The RSD\% and $E \%$ for intra- and inter-assay precision and accuracy, respectively, were less than $15 \%$.

\subsection{DZP analysis}

DZP and NOR concentrations were determined as previously described (Freire et al., 2005). Aliquots of $500 \mu \mathrm{L}$ rat plasma were added to $10 \mu \mathrm{L}$ of the IS $(100 \mu \mathrm{g} / \mathrm{mL}$ nitrazepam) and $2 \mathrm{~mL}$ of sodium hydrogen phosphate $\mathrm{pH} 9.0$, then extracted with $5 \mathrm{~mL} n$ hexane: ethanol (90:10, vol/vol) for $3 \mathrm{~min}$ in a vortex mixer. After centrifugation at $715 \mathrm{~g}$ for $10 \mathrm{~min}$, the organic phases were collected and evaporated to dryness $\left(60^{\circ} \mathrm{C}\right.$ under nitrogen flow). Furthermore, the residues were dissolved in $400 \mu \mathrm{L}$ of the mobile phase and injected into the chromatographic system. A HPLC Shimadzu ${ }^{\circledR}$ was coupled to the UV-vis detector, which was set at $228 \mathrm{~nm}$.

Chromatographic separations were achieved at a flow rate of $1.5 \mathrm{~mL} / \mathrm{min}$ on a CLC-ODS (M) column $(150 \mathrm{~mm} \times 4.6 \mathrm{~mm}$, $5 \mu \mathrm{m})$ (Shimadzu ${ }^{\circledR}$, Kyoto, Japan) and a guard column C18 $(4.0 \mathrm{~mm} \times 4.6 \mathrm{~mm}, 5 \mu \mathrm{m})$. The mobile phase was a mixture of potassium dihydrogen phosphate buffer $10 \mathrm{mmol} / \mathrm{L}, \mathrm{pH} 3.5$ and acetonitrile $(69: 31, \mathrm{vol} / \mathrm{vol})$, which was filtered and sonicated before use. The column oven temperature was $35^{\circ} \mathrm{C}$. Total run time was $25 \mathrm{~min}$. Standard curves were constructed using drug-free rat plasma spiked with DZP and NOR to provide a final concentration for each analyte of $50-1200 \mu \mathrm{g} / \mathrm{L}$ of plasma.

Quantification was based on the ratio of the chromatographic peak area of the analytes to the relative internal standard. The recoveries of both analytes were in the range of 76-93\%, regardless of DZP and NOR concentration. The RSD\% and E\% for intraand inter-assay precision and accuracy, respectively, were less than $15 \%$.

\subsection{Statistical analysis}

All statistical analyses were conducted using Prism software (version 5.03 for Windows, GraphPad Software, Inc., San Diego, California, USA). The results are reported as medians, means \pm standard errors (SEs) and 95\% confidence intervals (95\% CIs). Statistical comparisons of the experimental groups were performed using the nonparametric Mann-Whitney $U$ test. The homogeneity of the TOL exposure atmosphere in the inhalation chamber was verified via comparisons of their concentrations between the top and bottom planes using Student's unpaired $t$-test. A difference was considered to be statistically significant when the $p$-value was $<0.05$.

\section{Results}

\subsection{Exposure atmospheres}

The mean chamber concentrations for each sample collected in the inhalation chamber are provided in Table 1. The TOL concentrations in the inhalation chamber atmospheres were within 7\% of the desired concentration for all treatment groups. The stabil- 
Table 1

Results of the homogeneity and stability tests of the TOL exposure atmosphere in the nose-only inhalation chamber.

\begin{tabular}{|c|c|c|c|c|c|c|c|}
\hline \multirow[t]{2}{*}{ Nose port position } & \multicolumn{3}{|c|}{ 1st hour } & \multicolumn{2}{|c|}{ 3rd hour } & \multicolumn{2}{|c|}{ 6th hour } \\
\hline & Top & & Bottom & Top & Bottom & Top & Bottom \\
\hline Sample $1\left(\mathrm{mg} / \mathrm{m}^{3}\right)$ & 77.0 & & 76.0 & 77.8 & 82.0 & 74.2 & 77.7 \\
\hline Sample $2\left(\mathrm{mg} / \mathrm{m}^{3}\right)$ & 74.6 & & 69.7 & 81.6 & 79.8 & 85.5 & 81.7 \\
\hline Mean $\left(\mathrm{mg} / \mathrm{m}^{3}\right)$ & & 74.3 & & & & & \\
\hline RSD $\%$ & & 4.4 & & & & & \\
\hline Accuracy $^{\mathrm{a}}$ & & -0.9 & & & & & \\
\hline
\end{tabular}

a Accuracy $=[($ Experimental average concentration $/ T L V-T W A) \times 100]-100$.

ity and homogeneity of the two planes in the inhalation chamber atmosphere were maintained throughout the 6-h exposure period.

\subsection{HA and CR analysis}

The CR-corrected values of urinary HA are presented in Table 2. The mean level for the control group was equal to $0.21 \pm 0.02 \mathrm{~g} / \mathrm{g} \mathrm{CR}$. No statistically significant difference between the exposed (GTOL and GTOL/DZP) and control groups was observed for rats exposed to $20 \mathrm{ppm}$ TOL.

\subsection{0 -C analysis}

Table 2 shows the CR-corrected values of urinary 0 -C. A background level equal to $0.05 \pm 0.01 \mathrm{mg} / \mathrm{g} C \mathrm{C}$ was found in both groups of non-exposed rats (control and GDZP groups). The mean $o-C$ concentration excreted in urine in the GTOL group after exposure to $20 \mathrm{ppm}$ TOL (TLV-TWA) was approximately $0.19 \pm 0.03 \mathrm{mg} / \mathrm{g}$ $C R$. Urinary $o-C$ concentration was significantly reduced in the GTOL/DZP group $(0.11 \pm 0.01 \mathrm{mg} / \mathrm{g} \mathrm{CR})$ when compared to the GTOL group.

\subsection{DZP analysis}

The plasma concentrations of DZP and NOR are presented in Table 2. The plasma concentration of DZP was smaller than the expected value. The DZP + NOR mean levels for the GDZP and GTOL/DZP groups were equal to $165.5 \pm 10.80 \mu \mathrm{g} / \mathrm{L}$ and $140.5 \pm 11.5 \mu \mathrm{g} / \mathrm{L}$, respectively. No statistically significant difference was observed when the aforementioned groups were compared.

\section{Discussion}

Toxic effects arising from exposure to solvents and such effects on drug metabolism have been described in the literature (Cardoso et al., 2015; Mateus et al., 2008). However, studies on the possible influences of drugs on the solvents' metabolism are scarce. Decreased toxicity (antagonism) or increased toxicity (synergism) are expected and can result from pharmacokinetic and/or pharmacodynamic interactions (Chang et al., 2005). The present study reports for the first time the influence of DZP on urinary $o-C$ excretion when rats were exposed up to $20 \mathrm{ppm}$ TOL $(6 \mathrm{~h} /$ day, 5 days/week for 6 weeks) concomitantly with the drug.

In light of the obtained results, it can be concluded that the noseonly inhalation chamber was adequate to maintain homogeneity and stability in TOL concentration for the entire experiment. In addition to preventing the absorption of solvents by oral and dermal routes, the use of less solvent and better control over the inhalation atmosphere resulted in greater uniformity (Cardoso et al., 2015; Dorato, 1990).

The dose of DZP in our study represented a dose of $0.2 \mathrm{mg} / \mathrm{kg}$ in humans, which is comparable to the dose used in status epilepticus $(0.2-0.3 \mathrm{mg} / \mathrm{kg}$ ) (Walker et al., 1998). In a study conducted by Silvério et al. (2008), a mean plasma DZP concentration of $249.5 \mathrm{ng} / \mathrm{mL}$ was reported in patients who ingested $10 \mathrm{mg} /$ day $(\approx 0.2 \mathrm{mg} / \mathrm{kg})$ in long-term treatment. The DZP and NOR plasma levels obtained were somewhat lower than those in humans, possibly due to interspecies pharmacokinetic variability. However, the diazepam and nordiazepam levels in rat plasma were measured to confirm the intake and absorption of the drug as part of therapeutic drug monitoring.

Based on the urinary HA levels of all studied groups, it was not possible to state that DZP affects HA excretion. It is well-known that HA levels can be found in individuals who were not exposed to TOL in the range of $\mathrm{g} / \mathrm{g}$ CR. In a study conducted by Cosnier et al (2013), there was no significant elevation in HA level in rats after exposure at lower TOL concentrations (below $20 \mathrm{ppm}$ ). Thus, due to its non-specificity (as it may arise from other sources) and lack of sensibility at low exposure levels, this bioindicator is not trustable when exposure levels are below 30-50 ppm (Fustinoni et al., 2000).

Our study showed that the values of $o-C$ concentration obtained in the GTOL group are similar to those recommended for humans by the ACGIH (BEI: $0.3 \mathrm{mg} / \mathrm{g} \mathrm{CR}$, end of shift after several shifts). In a study conducted by Paiva et al. (2008), a urinary o-C concentration of $0.21 \mathrm{mg} / \mathrm{g} \mathrm{CR}$ was found in workers exposed to solvents in automotive repair shops. Indeed, TOL metabolism is similar in humans and rats. Although a significant amount of $o-\mathrm{C}$ might be present in urine of non-exposed subjects, it is not usable when they exposure level is below 2 ppm TOL (Cosnier et al., 2013; Inoue et al., 2008).

The urinary $o-C$ levels measured in the control and GDZP groups were comparable with those found in humans (Çok et al., 2003). However, in a comparison between the GTOL/DZP and GTOL groups, a decrease of approximately 50\% was found in urinary o-C levels when rats were co-exposed to TOL and DZP.

It is important to mention that CYP isoenzymes play a central role in the metabolism of drugs, environmental pollutants, and other xenobiotics (Hasler et al., 1999). According to Nakajima et al (1997), in human liver microsomes, the formation of benzyl alcohol is mediated by CYP2E1, 2B6, 2C8, and $1 \mathrm{~A} 2$ isoenzymes. Furthermore, CYP2C8 is involved in the formation of $o$ - and $p$-C. In the same study, CYP1A2, 2B6, and 2E1 were the major isoenzymes involved in $o$ - and $p$-C formation. Our results, which suggested a decrease in some CYP isoforms' activity, already have been discussed by other authors (Jiménez-Garza et al., 2012). These authors considered a decrease in CYP2E1 activity in TOL exposure to be a health risk, since workers are exposed to other substances that are potentially metabolized by the same CYP isoform. In a study conducted by the same authors, a possible alteration in CYP2E1 gene expression was related to co-exposure to tobacco and TOL (Jiménez-Garza et al., 2015).

Isoform CYP2E1 is in extremely low levels in the brain, however with relatively high activity, indicate that also occur toluene biotransformation in that tissue. Some authors suggest that the enhanced sensitivity of CYP2E1 in specific regions of the brain may be involved with the free radical induced neurotoxicity (Ferguson and Tyndale, 2011; Mattia et al., 1993; Yadav et al., 2006). 
Table 2

Results of the measurements of urinary HA and $o$-C levels as well as plasma concentrations of DZP and NOR in different treatment groups.

\begin{tabular}{|c|c|c|c|c|}
\hline & Control $^{\mathrm{a}}$ & $\mathrm{GTOL}^{\mathrm{a}}$ & GTOL/DZP & GDZP $^{\mathrm{a}}$ \\
\hline $\mathrm{HA}(\mathrm{g} / \mathrm{g} \mathrm{CR})$ & $\begin{array}{l}0.22 \\
0.21 \pm 0.02 \\
(0.16 \text { to } 0.25)\end{array}$ & $\begin{array}{l}0.23 \\
0.23 \pm 0.01 \\
(0.20 \text { to } 0.26)\end{array}$ & $\begin{array}{l}0.28 \\
0.25 \pm 0.04 \\
(0.15 \text { to } 0.36)\end{array}$ & $\begin{array}{l}0.24 \\
0.26 \pm 0.02 \\
(0.21 \text { to } 0.32)\end{array}$ \\
\hline$o-\mathrm{C}(\mathrm{mg} / \mathrm{g} \mathrm{CR})$ & $\begin{array}{l}0.05 \\
0.05 \pm 0.01 \\
(0.03 \text { to } 0.07)\end{array}$ & $\begin{array}{l}0.22 \\
\mathbf{0 . 1 9} \pm \mathbf{0 . 0 3}^{\text {c }} \\
(0.12 \text { to } 0.26)\end{array}$ & $\begin{array}{l}0.11 \\
\mathbf{0 . 1 1} \pm \mathbf{0 . 0 1}^{\mathrm{d}} \\
(0.08 \text { to } 0.15)\end{array}$ & $\begin{array}{l}0.05 \\
0.05 \pm 0.01 \\
(0.03 \text { to } 0.07)\end{array}$ \\
\hline $\mathrm{DZP}(\mu \mathrm{g} / \mathrm{L})$ & $\mathrm{UD}^{\mathrm{b}}$ & $\mathrm{UD}^{\mathrm{b}}$ & $\begin{array}{l}66.07 \\
64.14 \pm 5.34 \\
(49.31 \text { to } 78.97)\end{array}$ & $\begin{array}{l}81.93 \\
86.01 \pm 10.66 \\
(56.42 \text { to } 115.6)\end{array}$ \\
\hline $\operatorname{NOR}(\mu \mathrm{g} / \mathrm{L})$ & $\mathrm{UD}^{\mathrm{b}}$ & $\mathrm{UD}^{\mathrm{b}}$ & $\begin{array}{l}68.14 \\
73.85 \pm 7.67 \\
(52.56 \text { to } 95.15)\end{array}$ & $\begin{array}{l}85.04 \\
79.45 \pm 8.38 \\
(56.18 \text { to } 102.7)\end{array}$ \\
\hline $\mathrm{DZP}+\mathrm{NOR}(\mu \mathrm{g} / \mathrm{L})$ & $U^{b}$ & $\mathrm{UD}^{\mathrm{b}}$ & $\begin{array}{l}134.2 \\
140.5 \pm 11.5 \\
(108.5 \text { to } 172.4)\end{array}$ & $\begin{array}{l}168.9 \\
165.5 \pm 10.80 \\
(135.5 \text { to } 195.4)\end{array}$ \\
\hline
\end{tabular}

a $n=5$. Data are expressed as medians, means \pm SE and 95\% CI. Significantly different results are displayed in bold.

b Undetected (UD).

c $p<0.05$ vs. control group (Mann-Whitney test).

d $p<0.05$ vs. GTOL group (Mann-Whitney test).

As with TOL, the metabolism of diazepam involves a variety of CYPs, but basically CYP2B6, 2C8, 2C9, 3A4, and 3A5 isoenzymes are able to oxidize DZP, NOR, and TZ. Primarily CYP2C and 2B6 isoforms are related to N1-hydroxylation reactions, while CYP3A is involved in C3-hydroxylation of DZP (Acikgöz et al., 2009; Yang et al., 1998). According to Yang et al. (1998), CYP2E1 and 1A2 show weak but measurable activity in the oxidation of NOR and TZ.

In summary, our results suggested that possible enzymatic inhibition involving CYP isoenzymes (CYP2B6, CYP2C8, CYP2E1, and CYP1A2) affecting the metabolism of TOL and DZP and related to $o$ $\mathrm{C}$ formation could be responsible for the decrease in the excretion of this metabolite in urine and could result in a significant underestimation in a toluene occupational exposure assessment. Thus, this finding is relevant information to be considered in the biomonitoring of occupational toluene exposure when urinary $0-\mathrm{C}$ is the biological indicator adopted.

\section{Conclusion}

In conclusion, exposure to TOL ( $6 \mathrm{~h} /$ day, 5 days/week for 6 days) at a concentration of $20 \mathrm{ppm}$, which is equivalent to the TLV-TWA, in rats treated with $10 \mathrm{mg} / \mathrm{kg} /$ day DZP (by gavage) showed that DZP influences 0 -C excretion, reducing its urinary levels, probably via inhibition of CYP isoforms (CYP2B6, CYP2C8, CYP2E1, and CYP1A2) involved in the oxidative metabolism of TOL.

\section{Conflict of interest}

The authors declare that they have no conflict of interest.

\section{Ethical approval}

The procedure was approved by the Ethics Committee for Use of Animals of the Faculty of Pharmaceutical Sciences, São Paulo State University, Araraquara, number 27/2015.

\section{Acknowledgments}

This work was supported by CAPES (Higher Level Personnel Improvement Commission), financial support and scholarship to A.T. Silveira, and FAPEMIG (Foundation to support the research of Minas Gerais) grant number [APQ-01747-13].

\section{References}

Çok, I., Dagdelen, A., Gökçe, E., 2003. Determination of urinary hippuric acid and 0 -cresol levels as biological indicators of toluene exposure in shoe-workers and glue sniffers. Biomark 8, 119-127.

American Conference of Governmental Industrial Hygienists (ACGIH), 2015. TLVs® and BEIs®: Threshold Limit Values for Chemical Substances and Physical Agents \& Biological Exposure Indices. Cincinnati, Ohio.

Acikgöz, A., Karim, N., Giri, S., Schmidt-Heck, W., Bader, A., 2009. Two compartment model of diazepam biotransformation in an organotypical culture of primary human hepatocytes. Toxicol. Appl. Pharmacol. 234, 179-191.

Alldredge, B.K., Gelb, A.M., Isaacs, S.M., Corry, M.D., Allen, F., Ulrich, S., Gottwald, M.D., O'Neil, N., Neuhaus, J.M., Segal, M.R., Lowenstein, D.H., 2001. A comparison of lorazepam, diazepam, and placebo for the treatment of out of hospital status epilepticus. N. Engl. J. Med. 345, 631-637.

Antunes, M.V., Patuzzi, A.L.M., Linden, R., 2008. Determinação simultânea de creatinina e indicadores biológicos de exposição ao tolueno, estireno e xilenos em urina por cromatografia líquida de alta eficiência. Quím. Nova. 31, 1865-1868.

Beckley, J.T., Woodward, J.J., 2011. The abused inhalant toluene differentially modulates excitatory and inhibitory synaptic transmission in deep-layer neurons of the medial prefrontal cortex. Neuropsychopharmacology 36, 1531-1542.

Campbell, L., Wilson, H.K., Samuel, A.M., Gompertz, D., 1988. Interactions of m-xylene and aspirin metabolism in man. Brit. J. Ind. Med. 45, 127-132.

Cardoso, J.L.C., Lanchote, V.L., Pereira, M.P.M., Capela, J.M.V., Moraes, N.V., Lepera, J.S., 2015. Impact of inhalational exposure to ethanol fuel on the pharmacokinetics of verapamil, ibuprofen and fluoxetine as in vivo probe drugs for CYP3A, CYP2C and CYP2D in rats. Food Chem. Toxicol. 84, 99-105.

Chang, H.-Y., Yun, Y.-D., Yu, Y.-C., Shih, T.-S., Lin, M.-S., Kuo, H.-W., Chen, K.-M. 2005. The effects of simultaneous exposure to methyl ethyl ketone and toluene on urinary biomarkers of occupational N,N-dimethylformamide exposure. Toxicol. Lett. 155, 385-395.

Cosnier, F., Cossec, B., Burgart, M., Nunge, H., Brochard, C., Décret, M.-J., Rémy, A., 2013. Biomarkers of toluene exposure in rats: mercapturic acids versus traditional indicators (urinary hippuric acid and $o$-cresol and blood toluene). Xenobiotica 43, 651-660.

Døssing, M., Baelum, J., Hansen, S.H., Lundqvist, G.R., 1984. Effect of ethanol, cimetidine and propranolol on toluene metabolism in man. Int. Arch. Occup. Environ. Health. 54, 309-315.

Deutsche Forschungsgemeinschaft (DFG), 2015. List of MAK and BAT Values 2015: Maximum Concentrations and Biological Tolerance Values at the Workplace. WILEY-VCH, Weinheim.

Dorato, M.A., 1990. Overview of inhalation toxicology. Environ. Health Perspect. $85,163-170$.

U.S. Environmental Protection Agency (EPA), 2005. Toxicological review of toluene Washington, DC. https://www.epa.gov/sites/production/files/2014-03/ documents/toluene_toxicology_review_0118tr_3v.pdf. (accessed 13.07.16).

Ernstgård, L., Gullstrand, E., Johanson, G., Löf, A., 1999. Toxicokinetic interactions between orally ingested chlorzoxazone and inhaled acetone or toluene in male volunteers. Toxicol. Sci. 48, 189-196.

Ferguson, C.S., Tyndale, R.F., 2011. Cytochrome P450 enzymes in the brain: emerging evidence of biological significance. Trends Pharmacol. Sci. 32, $708-714$.

Freire, E.F., Miranda, J.L., Maia, P.P., Vieira, E.P., Borges, K.B., Siqueira, M.E.P.B., 2005. Diazepam e nordiazepam em plasma: métodos de extração líquido-líquido e 
em fase sólida no pré-tratamento de amostras para análise cromatográfica em fase líquida. Quím. Nova. 28, 773-776.

Fustinoni, S., Buratti, M., Giampiccolo, R., Brambilla, G., Foà, V., Colombi, A., 2000. Comparison between blood and urinary toluene as biomarkers of exposure to toluene. Int. Arch. Occup. Environ. Health 73, 389-396.

Hasler, J.A., Estabrook, R., Murray, M., Pikuleva, I., Waterman, M., Capdevila, J., Holla, V., Helvig, C., Falck, J.R., Farrell, G., Kaminsky, L.S., Spivack, S.D., Boitier, E., Beaune, P., 1999. Human cytochromes P450. Mol. Aspects Med. 20, 1-137.

Inoue, O., Kawai, T., Ukai, H., Maejima, Y., Fukui, Y., Ohashi, F., Okamoto, S., Takada, S., Sakurai, H., Ikeda, M., 2008. Limited validity of 0 -cresol and benzylmercapturic acid in urine as biomarkers of occupational exposure to toluene at low levels. Ind. Health. 46, 318-325.

Jiménez-Garza, O., Márquez-Gamiño, S., Albores, A., Caudillo-Cisneros, C., Carrieri, M., Bartolucci, G.B., Manno, M., 2012. CYP2E1 phenotype in Mexican workers occupationally exposed to low levels of toluene. Toxicol. Lett. 210, 254-263.

Jiménez-Garza, O., Baccarelli, A.A., Byun, H.M., Márquez-Gamiño, S. Barrón-Vivanco, B.S., Albores, A., 2015. CYP2E1 epigenetic regulation in chronic, low-level toluene exposure: relationship with oxidative stress and smoking habit. Toxicol. Appl. Pharmacol. 286, 207-215.

Lee, H.S., Yang, M., 2008. Review: applications of CYP-450 expression for biomonitoring in environmental health. Environ. Health. Prev. Med. 13, 84-93.

Ministério do Trabalho e Emprego (MTE), 2014. NR-15: Atividades e operações insalubres Brasília, Brazil. http://trabalho.gov.br/images/Documentos/SST/NR/ NR15/NR15-ANEX015.pdf. (accessed 26.07.16).

Mateus, F.H., Lepera, J.S., Marques, M.P., Boralli, V.B., Lanchote, V.L., 2008 Reduction of enantioselectivity in the kinetic disposition and metabolism of verapamil in rats exposed to toluene. Can. J. Physiol. Pharmacol. 86, 232-239.

Mattia, C.J., Adams, J.D., Bondy, S.C., 1993. Free radical induction in the brain and liver by products of toluene catabolism. Biochem. Pharmacol. 46, 103-110.

Nakajima, T., Wang, R.S., 1994. Mini review: induction of cytochrome P450 by toluene. Int. J. Biochem. 26, 1333-1340.

Nakajima, T., Wang, R.S., Elovaara, E., Gonzalez, F.J., Gelboin, H.V., Raunio, H., Pelkonen, O., Vainio, H., Aoyama, T., 1997. Toluene metabolism by cDNA-Expressed human hepatic cytochrome P450. Biochem. Pharmacol. 53, 271-277.
Netto, D.C., Reis, R.M., Mendes, C.B., Gomes, P.C.F.L., Martins, I., Siqueira, M.E.P.B. 2008. Headspace solid-phase microextraction procedure for gas-chromatography analysis of toluene in urine. J. Braz. Chem. Soc. 19, 1201-1206.

Paez-Martinez, N., Aldrete-Audiffred, J., Gallardo-Tenorio, A., Castro-Garcia, M., Estrada-Camarena, E., Lopez-Rubalcava, C., 2013. Participation of GABA $A_{A}$, $\mathrm{GABA}_{\mathrm{B}}$ receptors and neurosteroids in toluene-induced hypothermia: evidence of concentration - dependent differences in the mechanism of action. Eur. J. Pharmacol. 698, 178-185.

Paiva, M.J.N., Martins, I., Siqueira, M.E.P.B., 2008. Analysis of ortho-cresol in urine by solid phase microextraction-capillary gas chromatography. J. Braz. Chem. Soc. $18,1034-1039$

Silvério, A.C.P., Urias, T.S., Martins, I., Siqueira, M.E.P.B., 2008. Correlation between diazepam in plasma and dose in patients in long-term treatment. Latin Am. J. Pharm. 27, 766-770.

Sweetman, S.C., 2009. Martindale: The Complete Drug Reference. Pharmaceutica Press, London.

Truchon, G., Tardif, R., Brodeur, J., 1999. o-Cresol: a good indicator of exposure to low levels of toluene. Appl. Occup. Environ. Hyg. 10, 677-681.

Walker, M.C., Tong, X., Brown, S., Patsalos, P.N., 1998. Comparison of single and repeated dose pharmacokinetics of diazepam. Epilepsia 39, 283-289.

Wang, R.S., Nakajima, T., 1991. Kinetic studies on toluene metabolism in ethanol and phenobarbital induced rat liver microsomes in vitro. Arch. Toxicol. 65, 39-44.

Wang, R.S., Nakajima, T., 1992. Effects of ethanol and phenobarbital treatments on the pharmacokinetics of toluene in rats. Br. J. Ind. Med. 49, 104-112.

Win-Shwe, T.T., Fujimaki, H., 2010. Mini review: neurotoxicity of toluene. Toxicol. Lett. 198, 93-99.

Yadav, S., Dhawan, A., Singh, R.L., Seth, P.K., Parmar, D., 2006. Expression of constitutive and inducible cytochrome P450 2E1 in rat brain. Mol. Cell. Biochem. 286, 171-180.

Yang, T.J., Shou, M., Korzekwa, K.R., Gonzalez, F.J., Gelboin, H.V., Yang, S.K., 1998 Role of cDNA-expressed human cytochromes P450 in the metabolism of diazepam. Biochem. Pharmacol. 55, 889-896. 